\title{
Erratum to: Notch3 overexpression associates with poor prognosis in human non-small-cell lung cancer
}

Yuan-zi Ye $\cdot$ Zhi-hong Zhang $\cdot$ Xiao-yun Fan •

Xiao-lan Xu • Mei-li Chen • Bo-wen Chang •

Yan-bei Zhang

Published online: 5 September 2013

(C) Springer Science+Business Media New York 2013

Erratum to: Med Oncol (2013) 30:595

DOI 10.1007/s12032-013-0595-7

The authors state that the published Fig. 3 and curve labels are reversed. The corrected figure appears below.
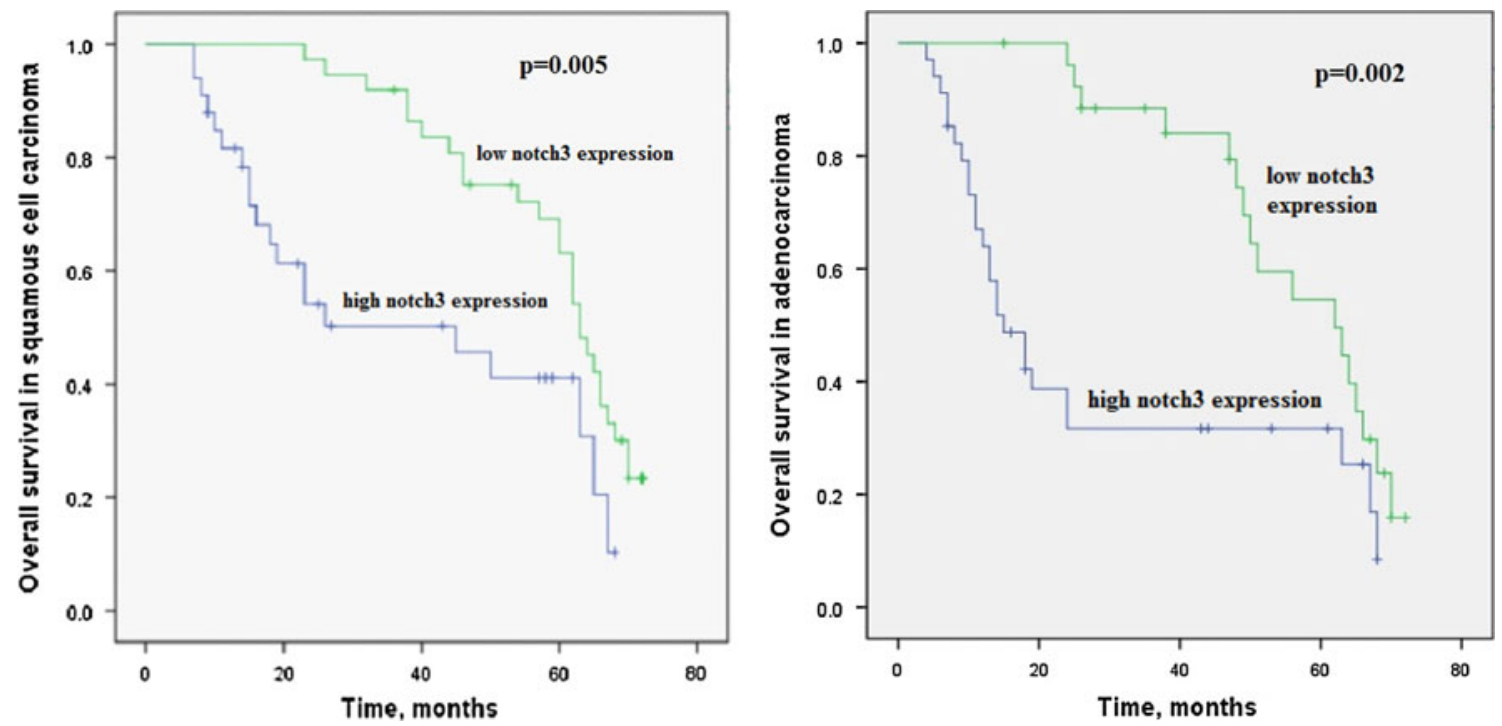

Fig. 3 Kaplan-Meier curves of survival patients with the Notch3 expression. The log-rank test was used to calculate $P$ values

The online version of the original article can be found under doi:10.1007/s12032-013-0595-7.

Y. Ye $\cdot$ Z. Zhang $\cdot$ X. Fan $\cdot$ X. Xu $\cdot$ M. Chen $\cdot$ B. Chang $\cdot$

Y. Zhang (ه)

Department of Respiratory Medicine, Anhui Geriatric Institute,

The First Affiliated Hospital of Anhui Medical University, Hefei,

Anhui 230022, People's Republic of China

e-mail: zhangyanbei1963@126.com 